\title{
Reversible Cycling of Graphite Electrode in Propylene Carbonate Electrolyte Enabled by Ethyl Isothiocyanate
}

Xiaolong Li,,* Limin Guo, ,* Jing Li,† Erkang Wang,

Ke Sun,,$^{*}$ Chuntai Liu, and Zhangquan Peng $\S, \|, \Delta^{\star}$

$\dagger$ State Key Laboratory of Electroanalytical Chemistry, Changchun Institute of Applied Chemistry, Chinese Academy of Sciences, Changchun 130022, China

$\$$ University of Science and Technology of China, Hefei 230026, China

§ Laboratory of Advanced Spectro-electrochemistry and Li-ion Batteries, Dalian Institute of Chemical Physics, Chinese Academy of Sciences, Dalian 116023, China

I Key Laboratory of Materials Processing and Mold (Zhengzhou University), Ministry of Education, National Engineering Research Center for Advanced Polymer Processing Technology, Zhengzhou University, Zhengzhou 450002, China

|| School of Applied Physics and Materials, Wuyi University, Jiangmen 529020, China

$\triangle$ Tianmu Lake Institute of Advanced Energy Storage Technologies Co. Ltd., Liyang, 213300, China

*Corresponding author

E-mail: lmguo@ciac.ac.cn; ekwang@ciac.ac.cn; kesun3@dicp.ac.cn; zqpeng@dicp.ac.cn 


\section{Supplementary Note 1}

The direct verification of reversible $\mathrm{Li}^{+}$ion intercalation into and de-intercalation out of the graphite electrode in the 2\% EITC-PC electrolyte was executed by an in-situ Raman study. Figure S1 presents the variation of Raman spectra of graphite electrode during the chargedischarge process. Upon charge, the major peak of the pristine graphite at $1580 \mathrm{~cm}^{-1}$ is initially stationary but then broadened and shifted toward higher frequencies after the voltage reaches below $0.2 \mathrm{~V}$, which corresponds to the formation of dilute stage 1 and its conversion to stage 4 of graphite electrode. Once the voltage passes $0.11 \mathrm{~V}$, two new peaks at $1575 \mathrm{~cm}^{-1}$ and 1602 $\mathrm{cm}^{-1}$ appear and increase at the expense of the original peak, which is correlated with the consecutively phase transitions stage 4 -stage 3 and stage 3 -stage $2 \mathrm{~L}$. After the voltage is decreased to $0.07 \mathrm{~V}$ and lower, the peak at $1602 \mathrm{~cm}^{-1}$ gradually diminishes, which indicates the phase transitions from stage $2 \mathrm{~L}$ to stage 2 . Finally, all original peaks were entirely missing and a new broad line appeared around $1500 \mathrm{~cm}^{-1}$ after the voltage drops below $0.039 \mathrm{~V}$, which reflects the final phase transition from stage 2 to stage 1 of graphite. During the discharge process, the above evolution of peak intensity and position were retrospectively observed. This result provides compelling evidence for the reversibility of graphite in EITC-PC electrolyte.

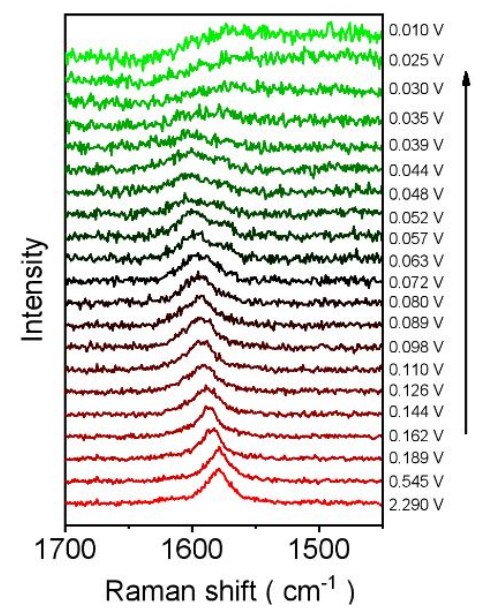


Figure S1. In-situ Raman spectra of a graphite electrode during charge (left) and discharge (right) in 2\% EITC-PC electrolyte.

a

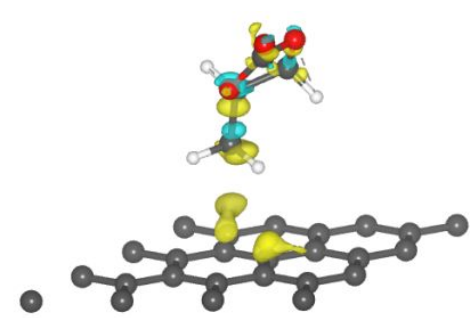

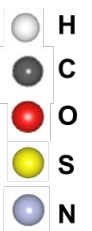

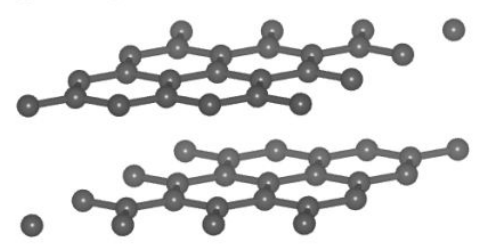

b

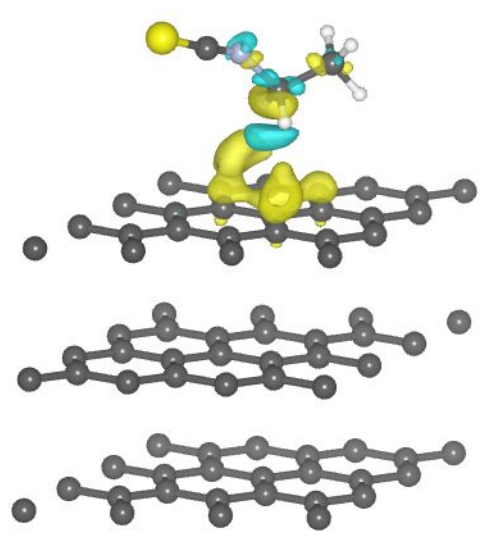

Figure S2. The charge density difference in the optimized adsorption geometry of (a) PC and (b) EITC on graphite surface. The yellow and blue isosurfaces represent charge accumulation and charge depletion in space, respectively. The isosurface level is $0.0002 \mathrm{au}$. 


\section{Supplementary Note 2}

Figure S3 displays the ${ }^{19} \mathrm{~F}$ ssNMR measurements performed on graphite electrode retrieved from the Li-graphite cells charged in STD-PC and 5\% EITC-PC electrolytes. In these two electrolytes, the F-containing species in the SEI are formed from the decomposition of $\mathrm{LiPF}_{6} . \mathrm{LiF}(\sim 204 \mathrm{ppm})$ and $\mathrm{PO}_{2} \mathrm{~F}_{2}^{-}(\sim 80 \mathrm{ppm})$ species are detected in both SEIs. Relatively, the LiF signal is much more pronounced in the 5\% EITC-PC electrolyte, consistent with the XPS results.

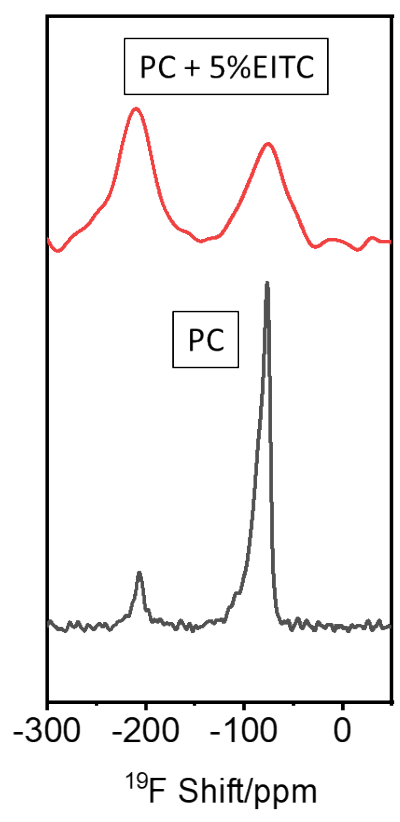

Figure S3. ${ }^{19} \mathrm{~F}$ ssNMR spectra collected on graphite electrodes charged in (black) STD-PC and (red) 5\% EITC-PC electrolytes. 

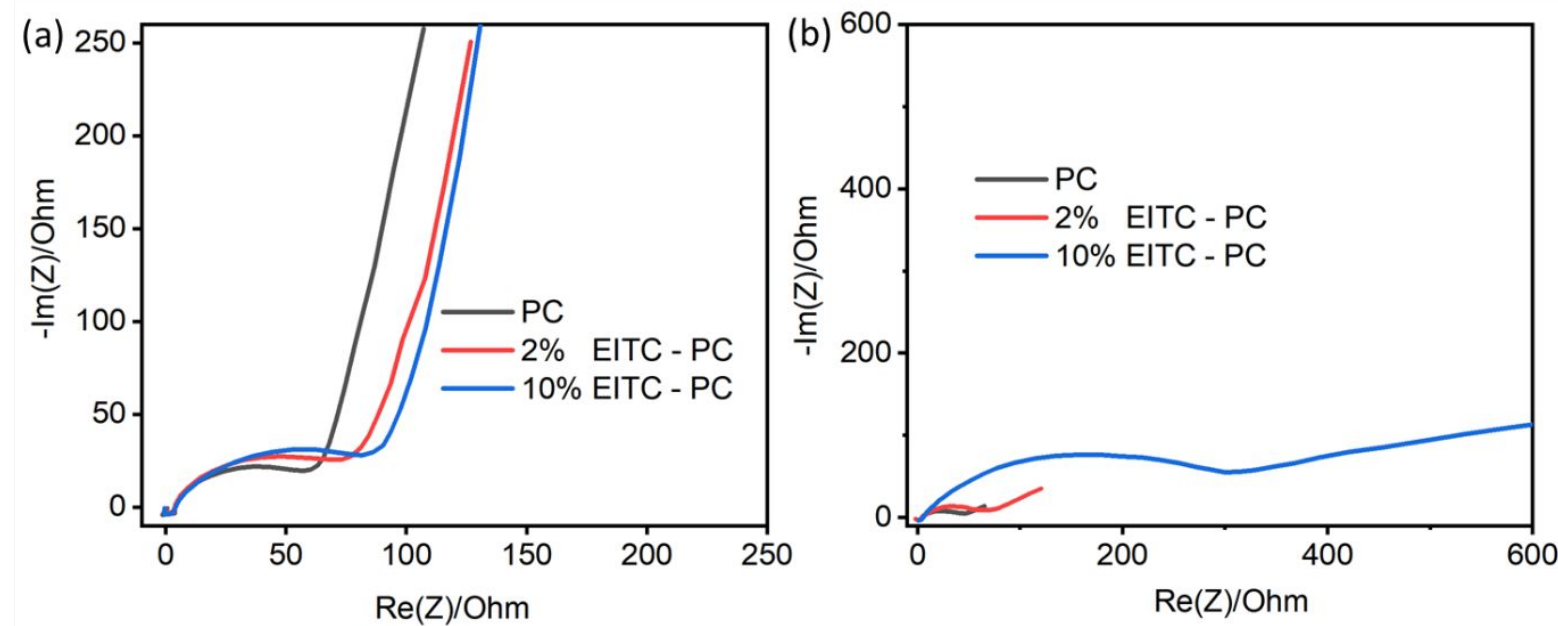

Figure S4. Impedance spectra of Li-graphite half cells with different electrolytes. (a) OCV condition; (b) after 2 cycles at C/10, the PC group was charged at C/10 for 40 hours because of the infinite plateau at $0.8 \mathrm{~V}$ vs. $\mathrm{Li}^{+} / \mathrm{Li}$.

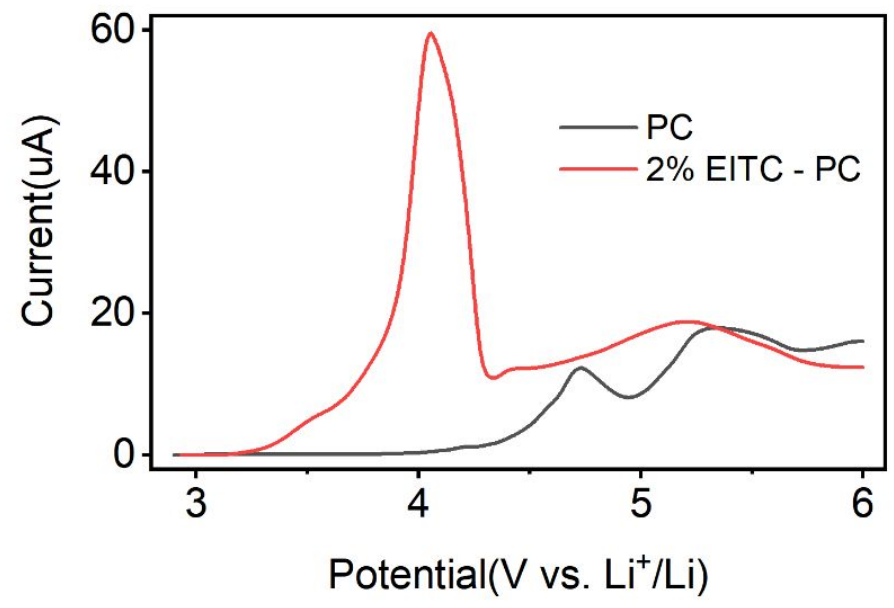

Figure S5. LSV test results of the PC-electrolyte and the 2\% EITC-PC electrolyte. 


\section{Table S1.}

The table compiles the works with the standard 1.0 M electrolyte concentration and the concentrations of the additives are less than $10 \mathrm{wt} \%$. The table excludes the cosolvent studies (PC $50 \mathrm{wt} \%$ ) and does not include the additive studies that only show cyclic voltammetric data.

\begin{tabular}{|c|c|c|c|}
\hline$\#$ & Publications & $\begin{array}{c}\text { Name of } \\
\text { Additive }\end{array}$ & Performance \\
\hline 1 & $\begin{array}{c}\text { Journal of The } \\
\text { Electrochemical } \\
\text { Society } 146(1999) \\
470\end{array}$ & $\begin{array}{c}\text { Ethylene } \\
\text { sulfite }\end{array}$ & $1^{\text {st }}$ cycle, $429 \mathrm{mAh} \mathrm{g}^{-1}$ at $0.05 \mathrm{C}$, no cycling data. \\
\hline 2 & $\begin{array}{c}\text { Journal of Power } \\
\text { Sources } 119-121 \\
(2003) 368\end{array}$ & Acrylonitrile & $2^{\text {nd }}$ cycle, $350 \mathrm{mAh} \mathrm{g}^{-1}, 3^{\text {th }}$ cycle to $325 \mathrm{mAh} \mathrm{g}^{-1}$ at \\
$0.05 \mathrm{C}$.
\end{tabular}


